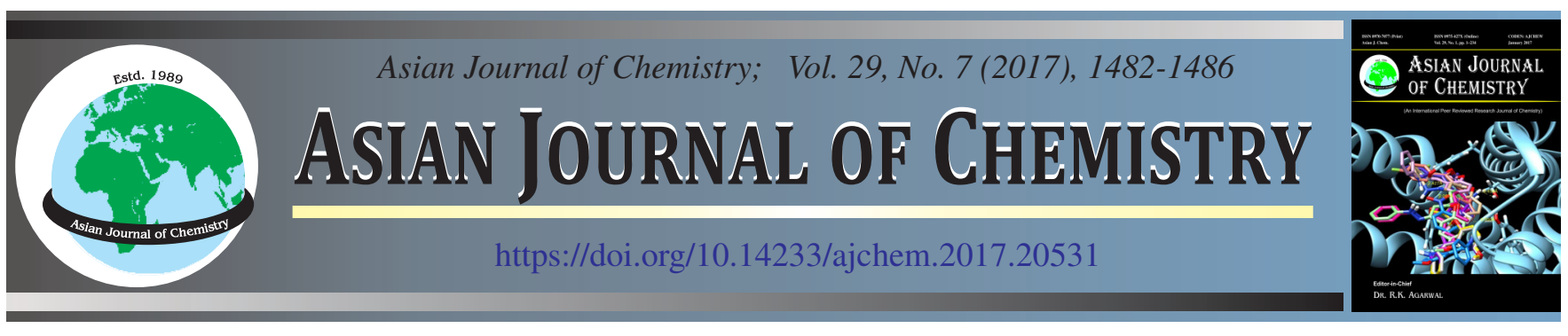

\title{
Bioanalytical Method Development and Validation for Quantitative Estimation of Valsartan by LC-MS/MS in Human Plasma
}

\author{
Krishna Chinthala ${ }^{1, *}$, Prasad Kancherla ${ }^{2}$ and Pramod Kumar ${ }^{2}$
}

${ }^{1}$ Environmental Protection Training and Research Institute, 91/4, Gachibowli, Hyderabad-500 032, India

${ }^{2}$ Centre for Chemical Sciences and Technology, Institute of Science \& Technology, Jawaharlal Nehru Technological University Hyderabad, Kukatpally, Hyderabad-500 085, India

*Corresponding author: E-mail: krishfdg@gmail.com; lalubpharm@gmail.com

An accurate, precise LC-MS/MS method has been developed and validation for quantitative estimation of valsartan using irbesartan as internal standard in human plasma. The method was established based on the HPLC separation on Zorbax SB-C $18,4.6 \times 50 \mathrm{~mm}, 5 \mu \mathrm{m}$ (Make: Agilent technologies) column at $40{ }^{\circ} \mathrm{C}$ using HPLC methanol: $0.1 \%$ formic acid (80:20, v/v) at a flow rate of $1 \mathrm{~mL} / \mathrm{min}$. The total chromatographic run time was $2.5 \mathrm{~min}$ with retention time of $1.40 \mathrm{~min}$ for valsartan. All quality control samples of analytes and internal standard was detected with LC-MS/MS system in multiple reactions monitoring mode. The method was validated according to USFDA guidelines. The calibration curves obtained were found to be linear over the concentration range of 50.85 to $12046.60 \mathrm{ng} / \mathrm{mL}$. Recovery studies were conducted for spiked plasma samples and mean \% recoveries were ranged from 75.39-79.44 \%. The results of within the batch and between the batch precision and accuracy were found within the limits of acceptance. The proposed LC-MS/MS method can successfully applied for the pharmacokinetic studies.

Keywords: Valsartan, LC-MS/MS, Bioanalytical, Irbesartan.

\section{INTRODUCTION}

Valsartan is an antihypertensive agent and mainly used to reduce the elevated blood pressure in hypertensive patients. It is also used in the treatment of systolic dysfunction, heart failure, myocardial infarction and coronary artery disease [1]. Valsartan is chemically [2] (S)-3-methyl-2-(N-\{[2'- $(2 \mathrm{H}-$ 1,2,3,4-tetrazol-5-yl)biphenyl-4-yl]methyl $\}$ pentanamido) butanoic acid (Fig. 1). It is an angiotensin II receptor (AT) blocker particularly has high affinity to bind AT1 subtype receptor. Valsartan produce vasodilatation effect on blood vessels and decrease in vascular resistance and blood pressure by selectively inhibits the binding of angiotensin II to AT1, which is found in many tissues such as vascular smooth muscle and the adrenal glands [3-6].

Literature survey revealed that few analytical methods based on HPLC [7-12] are reported for the determination of valsartan in biological samples. Conventional HPLC methods have the limitations in chromatographic run time, specificity and sensitivity compared with LC-MS/MS methods. The advantages of LC-MS/MS system are performing multiple reaction monitoring (MRM) for detection of individual species from a complex mixture, Characterization and quantitation of metabolites more quickly and easily. Similarly many LC-MS [13-19] methods have been reported for the determination of valsartan alone or in combination with other drugs in variety of biological samples.<smiles>CCCCC(=O)N(Cc1ccc(-c2ccccc2-c2nn[nH]n2)cc1)[C@@H](C(=O)O)C(C)C</smiles>

Fig. 1. Chemical structures of valsartan

\section{EXPERIMENTAL}

Valsartan and irbisartan were obtained from Hetero Drugs Limited India. Ammonium acetate, dimethyl sulfoxide and formic acid were obtained from Merck (Bangalore, India). HPLC grade water was obtained from Merck Ltd, Mumbai, 
India. Methanol and formic acid (HPLC grade) obtained from Merck Ltd, Mumbai, India. Plasma batches containing $\mathrm{K}_{2}$ EDTA control plasma was obtained from Deccan Pathalogical Labs, Hyderabad, India. Strata-X $33 \mu \mathrm{M}$ Polymeric sorbent were obtained from Phenomenex.

LC-MS/MS instrumentation and chromatographic conditions: A Shimadzu LC10AT HPLC system coupled to AB Sciex API-4000 mass spectrometer (Applied Biosystems, Ontario, Canada), equipped with an LC- of two LC- 10AT VP pumps, SIL-HTc autosampler, VP CTO- 10AS VP column oven and online DGU-20A3 solvent degasser. The samples solutions were run through Zorbax SB-C $18,4.6 \times 50 \mathrm{~mm}, 5$ $\mu \mathrm{m}$ (Make: Agilent technologies) column. The mobile phase consisted of HPLC grade methanol: $0.1 \%$ formic acid (80:20, $\% \mathrm{v} / \mathrm{v})$ was delivered. For isocratic, the flow rate of mobile phase was set at $1 \mathrm{~mL} / \mathrm{min}$. The analysis was performed with an electrospray ion interface operating in positive mode using nitrogen as the nebulizer, auxiliary, collision and curtain gas. Data acquisition and processing was performed using analyst software (version 1.4.2, Applied Biosystems, Ontario, Canada).

Preparation of standard stock solution of valsartan: Weighed accurately about $10 \mathrm{mg}$ of valsartan working standard and transferred to $10 \mathrm{~mL}$ clean and dry volumetric flask. Add 5 $\mathrm{mL}$ of methanol (HPLC grade) to dissolve the working standard and then make up the final volume with the same methanol to produce concentration of $1 \mathrm{mg} / \mathrm{mL}$. The stock solutions were diluted to suitable concentrations using methanol for spiking into plasma to obtain calibration curve (CC) standards, quality control (QC) samples and DIQC samples.

Preparation of stock solution and working solution of internal standard: Weighed accurately about $10 \mathrm{mg}$ of irbesartan working standard and transferred to $10 \mathrm{~mL}$ clean and dry volumetric flask. Add $5 \mathrm{~mL}$ of methanol (HPLC grade) to dissolve the working standard and then make up the final volume with the same methanol to produce concentration of $1 \mathrm{mg} / \mathrm{mL}$. The internal standard stock solutions were diluted to suitable concentrations using methanol for spiking into plasma to obtain calibration curve (CC) standards, quality control (QC) samples and DIQC samples.

Solid phase extraction procedure: Solid phase extraction was used to isolate valsartan and its internal standard (IS) from human plasma. All the frozen samples should be thaw and allowed to equilibrate at room temperature prior to analysis. $50 \mu \mathrm{L}$ plasma spiked with $10 \mu \mathrm{L}$ of internal standard dilution. Then swirl the fluid for $2 \mathrm{~min}$ and added $500 \mu \mathrm{L}$ of water. Load the entire content of the sample in to Strata X $33 \mu$ m polymeric sorbent $(30 \mathrm{mg} / 1 \mathrm{~mL})$ cartridges that were pre-conditioned with $1.0 \mathrm{~mL}$ of HPLC grade methanol followed by $0.5 \%$ formic acid buffer.

\section{RESULTS AND DISCUSSION}

LC-MS/MS optimized conditions: The main objective of the present work is to develop a simple, sensitive, rapid and economic LC-MS method of valsartan in human plasma. In optimization of chromatographic conditions, a series of trials were conducted using acetonitrile, phosphate, acetate and citrate buffers with different $\mathrm{pH}$ ranges to separate the drug samples from human plasma. The chromatographic conditions were optimized and the acceptable retention and separation of valsartan was obtained using the optimized mobile phase consisting, HPLC grade methanol: $0.1 \%$ formic acid (80:20, $\% \mathrm{v} / \mathrm{v}$ ) at a flow rate of $1 \mathrm{~mL} / \mathrm{min}$ and injection volume of 10 $\mu \mathrm{L}$. A simple solid-liquid extraction method has been employed for the extraction of valsartan and irbesatran from human plasma. The LC-MS/MS method described here satisfies the requirement of routine analyses since it has a short run time (2.5 min), which has advantages over other methods described in the literature. The mass spectroscopy optimization was performed by injecting the plasma samples of analyte along with internal standard and their $\mathrm{m} / \mathrm{z}$, value was as 436.40 and 429.40. The mass spectrum of valsartan and irbisartan was given in Figs. 2 and 3, respectively. The developed method gave a symmetric peak at a retention time of $1.40 \mathrm{~min}$ for valsartan.

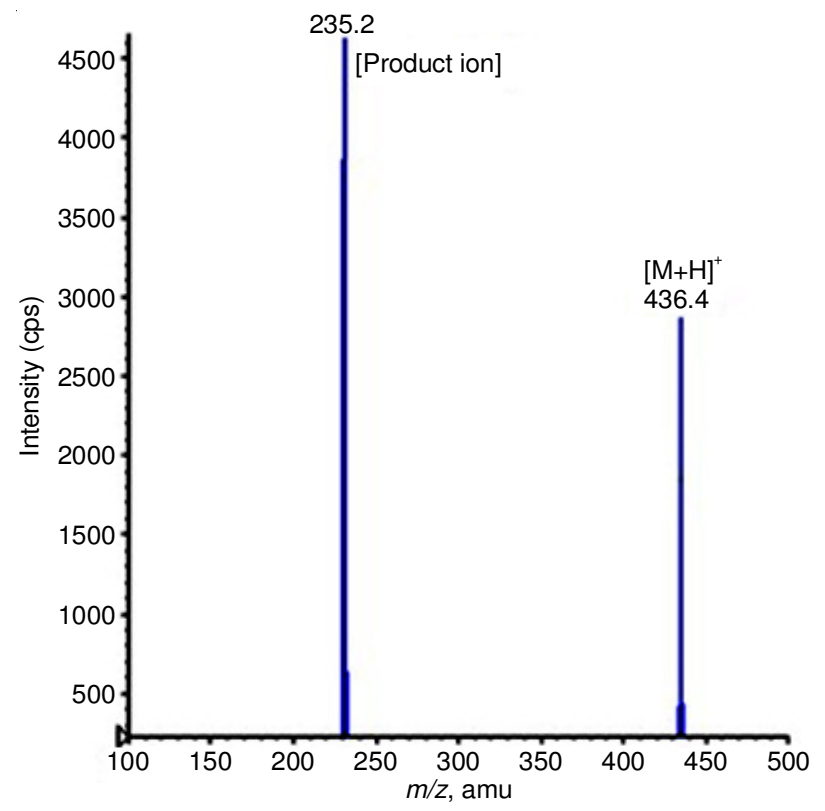

Fig. 2. Product ion mass spectra $[\mathrm{M}+\mathrm{H}]$ of valsartan

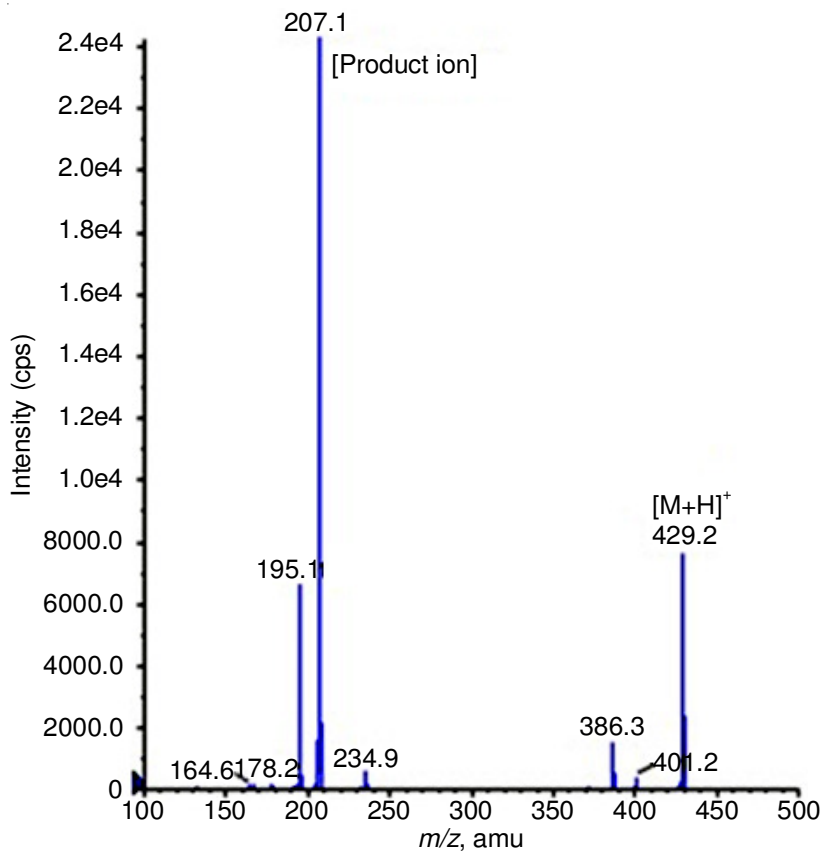

Fig. 3. Product ion mass spectra $[\mathrm{M}+\mathrm{H}]$ of irbisartan 
LC-MS/MS method validation: LC-MS/MS is one of the most powerful analytical tool for quantitative determination of drug samples in biological samples and pharmacokinetics studies. The proposed LC-MS/MS method was validated according to FDA guidelines. The fundamental parameters for validation include selectivity, linearity, accuracy, precision, matrix effect and stability.

Selectivity: To establish the selectivity of the method, possible interference at the retention time of valsartan and irbesartan due to endogenous plasma components were checked during the validation. Selectivity was performed by testing six batches of $\mathrm{K}_{2}$ EDTA blank plasma and the mass detection of extracted blank plasma gave good selectivity of both drug and internal standard. No interferences were found at the retention times of analytes and internal standard. The representative chromatograms of blank and standard valsartan and irbesartan were given in Figs. 4 and 5, respectively.
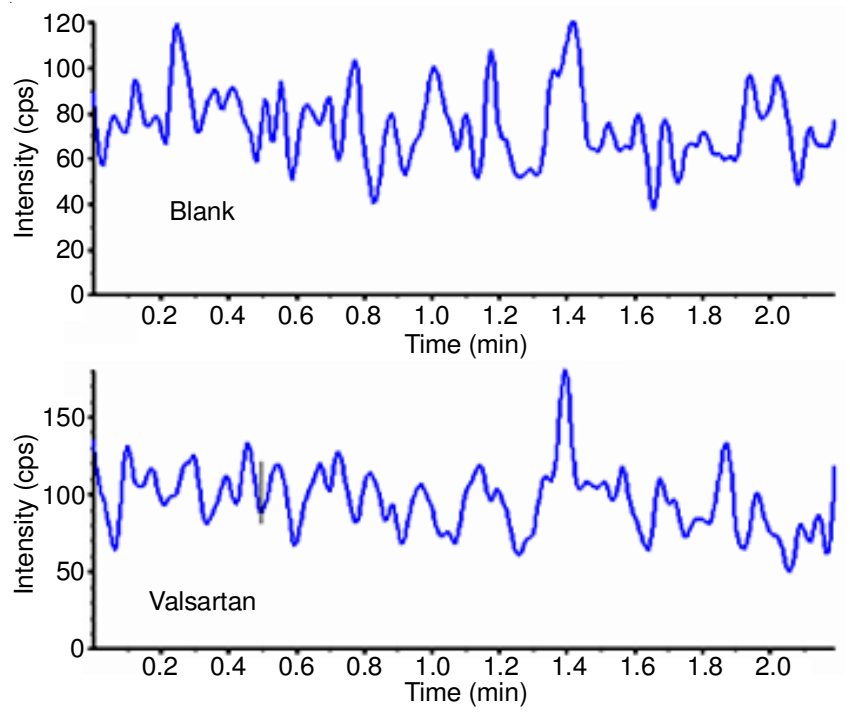

Fig. 4. A representative chromatogram of blank with valsartan

Accuracy and precision: The intraday and inter day accuracy and precision was assessed by analyzing six replicates at five different QC levels like LLOQ, LQC, MQC1, MQC2 and HQC. Accuracy and precision method performance was evaluated by determined by six replicate analyses for valsartan at four concentration levels, i.e., $151.36 \mathrm{ng} / \mathrm{mL}$ (LQC), 1455.56 ng/mL (MQC1), $6064.84 \mathrm{ng} / \mathrm{mL}$ (MQC2) and $10108.07 \mathrm{ng} / \mathrm{mL}$
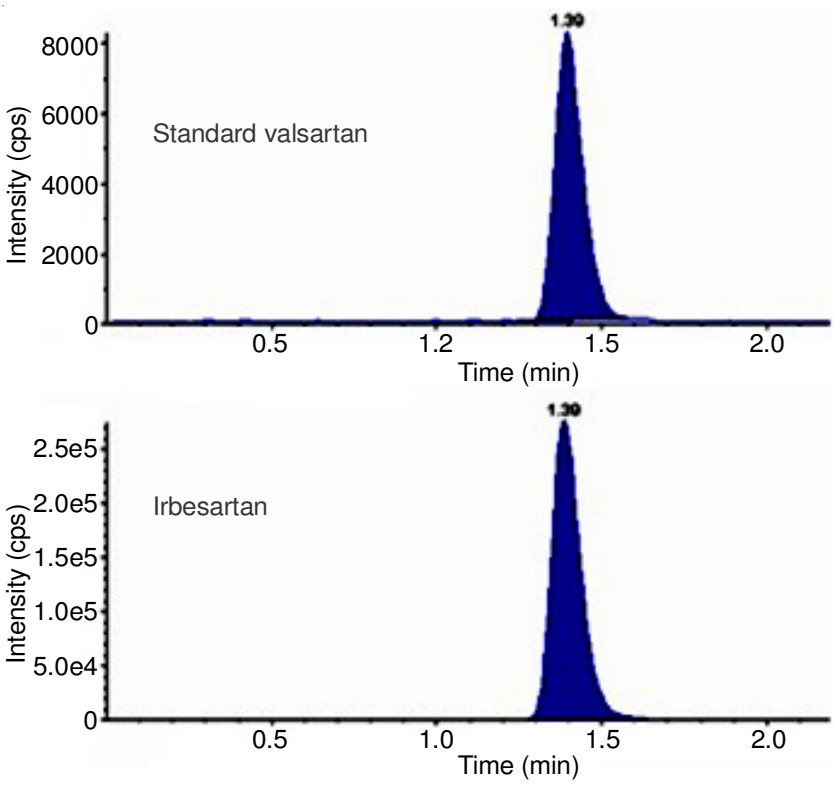

Fig. 5. A representative chromatogram of standard valsartan and irbesartan

(HQC). The intra-day and inter-day accuracy of plasma samples were assessed and excellent mean \% accuracy was obtained with range varied from 91.72-102.94 \% for intraday and $94.01-101.61 \%$ for inter-day, respectively. The precision $(\% \mathrm{CV})$ of the analytes and plasma samples were calculated and found to be 2.33-6.14 \% for intra-day and 3.63-6.22\% for inter day respectively (Table-1). The representative chromatograms of LQC, MQC and HQC samples were presented in Fig. 6(a-c).

\begin{tabular}{|c|c|c|c|c|}
\hline \multicolumn{5}{|c|}{$\begin{array}{l}\text { TABLE-1 } \\
\text { INTRA-DAY AND INTER-DAY ACCURACY AND } \\
\text { PRECISION VARIATION OF VALSARTAN }(\mathrm{n}=18)\end{array}$} \\
\hline \multirow{2}{*}{$\begin{array}{l}\text { Concentration } \\
(\mathrm{ng} / \mathrm{mL})\end{array}$} & \multicolumn{2}{|c|}{ Intra-day } & \multicolumn{2}{|c|}{ Inter-day } \\
\hline & $\begin{array}{l}\text { Accuracy } \\
(\%)\end{array}$ & $\begin{array}{l}\mathrm{CV} \\
(\%)\end{array}$ & $\begin{array}{c}\text { Accuracy } \\
(\%)\end{array}$ & $\begin{array}{l}\mathrm{CV} \\
(\%)\end{array}$ \\
\hline LQC-151.38 & 101.56 & 3.21 & 100.51 & 3.63 \\
\hline MQC1-1455.56 & 91.72 & 2.33 & 94.01 & 4.02 \\
\hline MQC-2606.84 & 98.86 & 6.41 & 101.61 & 6.22 \\
\hline HQC-10108.07 & 102.49 & 2.77 & 100.41 & 4.21 \\
\hline
\end{tabular}

Linearity: Calibration was found to be linear over the concentration range of 50.85 to $12046.60 \mathrm{ng} / \mathrm{mL}$ for valsartan (Fig. 7). The coefficient correlation $\left(\mathrm{r}^{2}\right)$ value was found
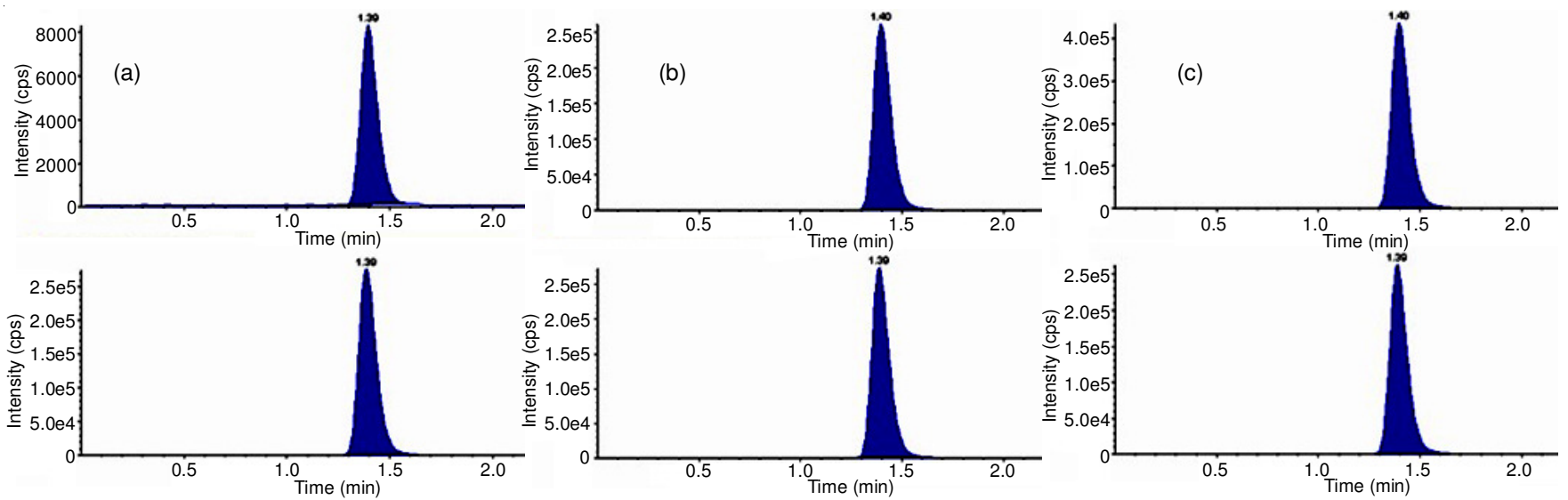

Fig. 6. Representative Chromatograms of standard Valsartan and Irbesartan at concentration (a) LQC (b) MQC) (c) HQC 


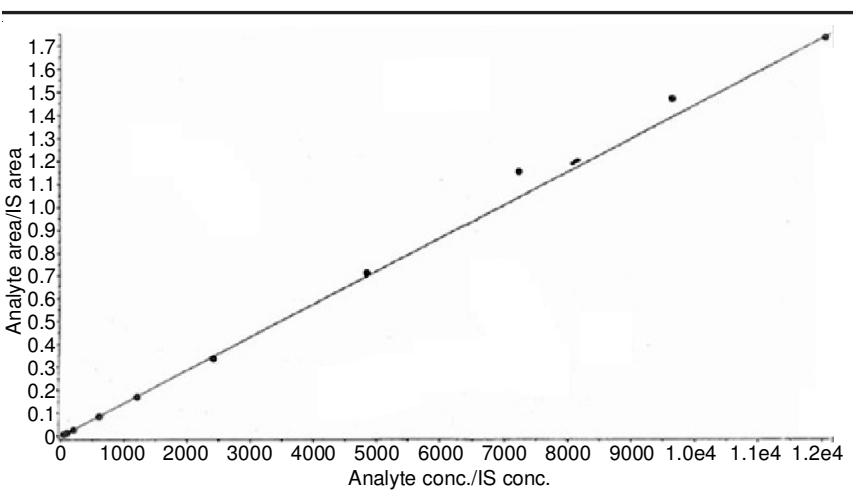

Fig. 7. A typical calibration curve of valsartan

consistently greater than 0.9950 in all the cases. This indicating linearity of results and an excellent correlation between peak area ratio for each concentration of analytes.

Recovery and matrix effect: Recovery was determined by measuring the peak areas obtained from prepared plasma samples with those extracted blank plasma spiked with standards containing the same area with known amount of valsartan. The overall mean recovery of valsartan was good and reproducible and found to be in the range of $77.05 \%$. Matrix effect played a vital role in the assessment of pharmacokinetic studies. It was expressed as internal standard normalized matrix factor and it was varied from 0.987-0.989 which was close to 1 which indicates there is no ionization suppression or enhancement in plasma samples (Table-2).

\begin{tabular}{cccc}
\multicolumn{4}{c}{ TABLE-2 } \\
EXTRACTION RECOVERY AND MATRIX \\
FACTOR FOR VALSARTAN $(\mathrm{n}=6)$
\end{tabular}

Dilution integrity: Twelve sets of dilution integrity samples were prepared by spiking about 1.75 time's of highest standard concentration $(21016.78 \mathrm{ng} / \mathrm{mL})$. These sample is further diluted by $1 / 2$ and $1 / 4$ times and analyzed. The $\%$ mean accuracy for dilution integrity of $1 / 2$ and $1 / 4$ was found to be $91.69 \%$ and $99.86 \%$, respectively. The $\% \mathrm{CV}$ for dilution integrity of $1 / 2$ and $1 / 4$ was found to be $1.87 \%$ and $2.77 \%$, respectively.

\section{Stability studies}

Bench top stability: In bench-top stability, six replicates of LQC \& HQC samples (151.36 and $10108.07 \mathrm{ng} / \mathrm{mL}$ ) were analyzed for $9 \mathrm{~h}$ at room temperature on the laboratory bench.
The $\%$ mean stability was calculated and found to $100.16 \%$ for LQC and $105.46 \%$ for HQC, respectively (Table-3).

Freeze thaw stability: Freeze and thaw stability should be assessed after 4 freeze and thaw cycles of LQC (low quality control) and HQC (high quality control) samples. The freezethaw stability studies were carried out at low and high quality control samples of valsartan and mean \% stability for LQC was calculated as $99.12 \%$ and for HQC it was calculated as $111.06 \%$ respectively which were well inside the acceptable ranges as per the guidelines (Table-3).

Short term stock solution stability: In the short term stock solution stability, three aliquots of MQC2 samples in six replicates were thawed at room temperature $\left(25^{\circ} \mathrm{C}\right)$ for $8 \mathrm{~h}$. Based on the results obtained it was found to be stable for $8 \mathrm{~h}$ when stored at room temperature. $\%$ mean stability of the valsartan was found to be $101.27 \%$ with precision range of 1.14 to $1.49 \%$. The $\%$ mean stability of the IS was found to be $101.92 \%$ with precision range of 1.44 to $1.81 \%$.

Long term stock solution stability: Long term stock solution stability for the valsartan and the irbisartan was determined at a concentration of QC-M2 level after a storage period of 25 days at $2-8{ }^{\circ} \mathrm{C}$ in refrigerator. The $\%$ mean stability of the valsartan was found to be $101.44 \%$. The $\%$ mean stability of the irbisartan was found to be $101.18 \%$.

Auto sampler stability: Auto sampler stability of the processed quality control samples was determined for a period of $48 \mathrm{~h}$ by storing them in auto sampler maintained at $10^{\circ} \mathrm{C}$. The $\%$ mean stability for LQC and HQC was found to be 99.10 and $106.21 \%$, respectively (Table-3).

Wet extraction stability: Wet extract stability of the spiked quality control samples was determined for a period of $44 \mathrm{~h}$ by storing them at room temperature. The $\%$ mean stability for LQC and HQC was found to be 96.58 and $107.93 \%$ (Table-3).

\section{Conclusion}

A new simple, sensitive and rapid LC-MS/MS method has been developed and validated for the simultaneous estimation of valsartan in human plasma samples over the concentration range of 50.85 to $12046.60 \mathrm{ng} / \mathrm{mL}$. The proposed method was validated for its parameters such as selectivity, selectivity, accuracy, precision and results obtained are found to be within the limits. The developed separation method produced acceptable values of recovery and results shows that the method is free from interferences of the excipients used in the formulation. Therefore the proposed method can be used for routine analysis of estimation of valsartan to a clinical pharmacokinetic study in human volunteers.

TABLE-3

STABILITY EXPERIMENTS OF VALSARTAN $(n=6)$

\begin{tabular}{|c|c|c|c|c|}
\hline Stability experiment & Storage conditions & QC level & Mean stability (\%) & $\mathrm{CV}(\%)$ \\
\hline \multirow{2}{*}{ Bench top } & \multirow{2}{*}{ Room temperature $(9 \mathrm{~h})$} & LQC & 100.16 & 2.87 \\
\hline & & HQC & 105.46 & 2.25 \\
\hline \multirow{2}{*}{ Freeze thaw } & \multirow{2}{*}{ After 4 FT cycles } & LQC & 99.12 & 2.83 \\
\hline & & $\mathrm{HQC}$ & 111.06 & 2.20 \\
\hline \multirow{2}{*}{ Auto sampler } & \multirow{2}{*}{ After $48 \mathrm{~h}$ storage at $10^{\circ} \mathrm{C}$} & LQC & 99.10 & 4.96 \\
\hline & & $\mathrm{HQC}$ & 106.21 & 2.37 \\
\hline \multirow{2}{*}{ Wet extraction } & \multirow{2}{*}{ After $44 \mathrm{~h}$ storage at room temperature } & LQC & 96.58 & 2.26 \\
\hline & & $\mathrm{HQC}$ & 107.93 & 1.07 \\
\hline
\end{tabular}




\section{ACKNOWLEDGEMENTS}

The authors are thankful to Environment Protection Training and Research Institute, Hyderabad, India and Jawaharlal Nehru Technological University Hyderabad, Hyderabad, India for providing necessary research facilities.

\section{REFERENCES}

1. M.J. O' Neil, A. Smith, P.E. Heckelman and J.F. Kinneary, The Merck Index: An Encyclopedia of Chemicals, Drugs and Biologicals, edn 14, p. 1767 (2006)

2. Matrindale, The Complete Drug Reference, Pharmaceutical Press, London, Chicago, edn 34, p. 1018 (2002).

3. J.H. Bauer and G.P. Reams, Arch. Intern. Med., 155, 1361 (1995); https://doi.org/10.1001/archinte.1995.00430130027004.

4. G. Flesch, P. Müller and P. Lloyd, Eur. J. Clin. Pharmacol., 52, 115 (1997); https://doi.org/10.1007/s002280050259.

5. R.L. Webb and M. de Gasparo, Exp. Clin. Cardiol., 6, 215 (2001).

6. C.D. Benge and J.A. Muldowney III, Expert Opin. Drug Metab. Toxicol., 8, 1469 (2012); https://doi.org/10.1517/17425255.2012.725721.

7. R.N. Sharma and S.S. Pancholi, Acta Pharm., 62, 45 (2012); https://doi.org/10.2478/v10007-012-0004-3.

8. T.S. Kepekci, J. Anal. Methods Chem., 179, 627 (2013).

9. G. Iriarte, O. Gonzalez, N. Ferreirós, M.I. Maguregui, R.M. Alonso and R.M. Jiménez, J. Chromatogr. B Analyt. Technol. Biomed. Life Sci., 877, 3045 (2009);

https://doi.org/10.1016/j.jchromb.2009.07.018.
10. S.S. Imam, A. Ahad, M. Aqil, Y. Sultana and A. Ali, J. Pharm. Bioallied Sci., 5, 61 (2013).

11. D.U. Vinzuda, G.U. Sailor and N.R. Sheth, Int. J. ChemTech Res., 2, 1461 (2010).

12. S. Ghanty, R. Das, S. Maiti and K.K. Sen, J. Pharm. Sci. Technol., 3, 88 (2014).

13. H.J. Shah, N.B. Kataria, G. Subbaiah and C.N. Patel, Chromatographia, 69, 1055 (2009); https://doi.org/10.1365/s10337-009-0950-1.

14. N. Koseki, H. Kawashita, H. Hara, M. Niina, M. Tanaka, R. Kawai, Y. Nagae and N. Masuda, J. Pharm. Biomed. Anal., 43, 1769 (2007); https://doi.org/10.1016/i.jpba.2006.12.030.

15. S.G. Gadepalli, P. Deme, M. Kuncha and R. Sistla, J. Pharm. Anal., 4, 399 (2014); https://doi.org/10.1016/i.jpha.2013.12.003.

16. A.V. Ramani, P. Sengupta and R. Mullangi, Biomed. Chromatogr., 23, 615 (2009); https://doi.org/10.1002/bmc.1161.

17. H. Li, Y. Wang, Y. Jiang, Y. Tang, J. Wang, L. Zhao and J. Gu, J. Chromatogr. B Analyt. Technol. Biomed. Life Sci., 852, 436 (2007); https://doi.org/10.1016/i.jchromb.2007.02.014.

18. P.S. Selvan, K.V. Gowda, U. Mandal, W.D. Solomon and T.K. Pal, J. Chromatogr. B Analyt. Technol. Biomed. Life Sci., 858, 143 (2007); https://doi.org/10.1016/j.jchromb.2007.08.016.

19. M. Levi, G. Wuerzner, E. Ezan and A. Pruvost, J. Chromatogr. B Analyt. Technol. Biomed. Life Sci., 877, 919 (2009); https://doi.org/10.1016/j.jchromb.2009.02.030. 